\title{
Coeficientes de Digestibilidade Aparente da Proteína e Energia de Alguns Ingredientes Utilizados em Dietas para o Pintado (Pseudoplatystoma coruscans)
}

\author{
Emílio Guedes Gonçalves ${ }^{1}$, Dalton José Carneiro²
}

\begin{abstract}
RESUMO - O presente trabalho foi desenvolvido com o objetivo de determinar os coeficientes de digestibilidade aparente da proteína e da energia dos principais alimentos utilizados na formulação de dietas para alevinos de pintado. Foram utilizados 600 alevinos com

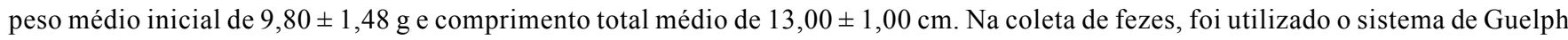
modificado. As 12 dietas-teste foram constituídas por 69,50\% de uma dieta de referência, 0,50\% de óxido de cromo (marcador inerte) e 30\% do ingrediente estudado. Após receberem as dietas teste durante três dias, os peixes foram transferidos para os aquários de coleta (incubadoras de fibra de vidro de 80 litros de capacidade), onde as fezes foram coletadas em intervalos de meia hora. Com base nos coeficientes de digestibilidade da fração protéica, os alimentos que apresentaram maior aproveitamento para esse nutriente foram: farinha de peixe (84,14\%), farelo de soja (67,10\%), milho (64,18\%) e farinha de vísceras de aves $(61,25 \%)$. Foram observados valores razoáveis somente para a digestibilidade do conteúdo energético em metade dos ingredientes estudados; para as farinhas de peixe, milho, soja integral tostada e os farelos de soja, de trigo e de arroz, os coeficientes médios foram: 72,80; 57,39; 64,95; 61,66; 53,20 e 51,84\%, respectivamente. A farinha de peixe foi o melhor ingrediente para o pintado (45,38\% PD e 2790,42 kcal ED $/ \mathrm{kg}$ ), seguido do farelo de soja (30,86\% PD e 2708,45 kcal ED/kg), da soja integral tostada (18,34\% PD e 3121,06 kcal ED $/ \mathrm{kg})$, do milho (5,86\% PD e 2691,53 kcal ED/kg) e do farelo de trigo $(8,08 \%$ PD e $2265,13 \mathrm{kcal} \mathrm{ED} / \mathrm{kg})$.
\end{abstract}

Palavras-chave: pintado, Pseudoplatystoma coruscans, digestibilidade, alimentos, proteína digestível, energia digestível

\section{Apparent Digestibility Coefficients of Protein and Energy of Some Ingredients Used in Diets for Pintado, Pseudoplatystoma coruscans (Agassiz, 1829)}

\begin{abstract}
The present work was developed in order to determine the protein and energy apparent digestibility coefficients of the principal ingredients used in the pintado juvenile diets. Six hundred juveniles with initial weight and total length means of $9.80 \pm 1.48 \mathrm{~g}$ and $13.00 \pm 1.00 \mathrm{~cm}$, respectively, were used. The modified Guelph system was appraised to collect feces. All the twelve test diets were constituted of $69.50 \%$ of the reference diet, $0.50 \%$ of chromium oxide used as inert marker, and $30 \%$ of the ingredient tested. After three days of feeding with the test diets, fish were transferred to the collect aquariums, where feces were collected in intervals of 30 minutes. Using digestibility of the protein, ingredients with best results in this nutrient were fish meal (84.14\%), soybean meal (67.10\%), corn (64.18\%) and chicken poultry by-product (61.25\%). Was only observed reasonable values for energy digestibility in half of the ingredients tested; for fish meal, corn, soybean (whole, toasted) and soybean meal of wheat and rice, the mean coefficients values were: $72.80,57.39,64.95,61.66,53.20$, and $51.84 \%$, respectively. Fish meal was the best ingredient available for pintado juveniles diet formulation (45.38\%DP and $2790.42 \mathrm{kcal} \mathrm{DE} / \mathrm{kg})$, followed by soybean meal (30.86\%DP and $2708.45 \mathrm{kcal}$ $\mathrm{DE} / \mathrm{kg}$ ), soybean (whole, toasted) (18.34\%DP and $3121.06 \mathrm{kcal} \mathrm{DE} / \mathrm{kg})$, corn (5.86\%DP and $2691.53 \mathrm{kcal} \mathrm{DE} / \mathrm{kg})$, and wheat meal $(8.08 \% \mathrm{DP}$ and $2265.13 \mathrm{kcal} \mathrm{DE} / \mathrm{kg})$.
\end{abstract}

Key Words: pintado, Pseudoplatystoma coruscans, digestibility, feedstuffs, digestible protein, digestible energy

\section{Introdução}

O pintado, Pseudoplatystoma coruscans, (Agassiz, 1829) é uma espécie da família Pimelodidae, encontrado freqüentemente nas Bacias dos Rios Paraguai-Uruguai e São Francisco. Apresenta ótima aceitação de mercado, devido à excelente palatabilidade e ausência de espinhos intramusculares em sua carne, além de poder atingir em um ano, peso duas vezes maior que o das espécies produzidas atualmente.

A reprodução de peixes do gênero Pseudoplatystoma vem sendo pesquisada desde o início da década de oitenta, mas só atingiu escala comercial no início da década de noventa. Apesar da tecnologia atual para a obtenção de alevinos, o maior desafio está sendo a sua alimentação em cativeiro,

\footnotetext{
1 Zootecnista, Mestre em Aquicultura, CAUNESP. Bolsista FAPESP. Via de Acesso Prof. Paulo Donato Castellane S/N. CEP: 14884-900 Jaboticabal, SP - Brasil. E.mail: emiliogoncalves@terra.com.br

2 Zootecnista, Prof. Departamento de Zootecnia da FCAV- UNESP/Jaboticabal. Via de Acesso Prof. Paulo Donato Castellane S/N. CEP: 14884-900, Jaboticabal, SP - Brasil. E.mail: daltonjc@caunesp.unesp.br
} 
devido ao alto custo, pelo seu hábito alimentar piscívoro, e principalmente, à falta de conhecimento de suas exigências nutricionais e digestibilidade dos alimentos utilizados na sua dieta, que levariam à maximização do aproveitamento dos nutrientes.

Em estudo feito na bacia hidrográfica do Rio Miranda, Resende et al. (1990) estudaram o conteúdo estomacal do pintado Pseudoplatystoma coruscans, da cachara Pseudoplatystoma fasciatum e do curimbatá (Prochilodus lineatus), e relataram que, em $92,6 \%$ dos pintados observados, encontraram basicamente traíras, Hoplias malabaricus, e outros peixes das ordens Characiformes e Siluriformes, indicando um hábito preferencialmente piscívoro. Seixas Filho et al. (2001) confirmaram que o arranjo intestinal do pintado é compatível com a maioria dos peixes carnívoros, uma vez que seu intestino é quase retilíneo, mas relatou que apresenta algumas particularidades, como circunvoluções das alças finais do intestino médio, que poderiam ser vistas como possíveis adaptações para um regime onívoro. Segundo os mesmos autores, as relações entre o arranjo das pregas mucosas e a velocidade de transporte do alimento no intestino médio sugerem que o padrão longitudinal com numerosas anastomoses retarda o avanço do alimento em sentido aboral, o que possibilita maior período de digestão e, conseqüentemente, maior aproveitamento dos nutrientes.

De acordo com Gonçalves (1998), o tempo de trânsito gastrointestinal de uma ração para alevinos de pintado, a $28^{\circ} \mathrm{C}$, foi de 7 horas e 30 minutos, e esta rápida passagem do alimento ocorre em funcão do curto trato digestivo, característico do hábito alimentar da espécie.

Em estudos de nutrição, os coeficientes de digestibilidade aparente são geralmente utilizados com o objetivo de determinar o valor nutricional de um alimento (Rodrigues, 1994). De acordo com McGoogan \& Reigh (1996), a digestibilidade do ingrediente de um alimento depende, primeiramente, da composição química e também da capacidade digestiva do animal para o alimento. Ela é de extrema importância para o atendimento das exigências nutricionais de uma espécie, uma vez que o conhecimento dos hábitos alimentares e o fornecimento de uma dieta equilibrada não são suficientes para assegurar resposta positiva no desempenho do animal (Souza, 1989).

$\mathrm{Na}$ atualidade, estão sendo exigidas maiores investigações acerca das exigências nutricionais de cada espécie, além de rigorosa formulação da dieta Albernaz, (2000). Sem os dados de digestibilidade dos nutrientes, os nutricionistas, arriscam-se em super-dosagens, principalmente de proteína bruta que elevam à sua ineficácia e ao alto custo de produção, ou em subdosagens, que podem reduzir as taxas de crescimento e, de outras formas, o desempenho dos peixes.

Existem várias metodologias para coleta de fezes em estudos de nutrição com peixes. De acordo com Sallum (2000), o seu desenvolvimento visa, principalmente, contornar situações tais como o estresse dos animais pelo manuseio nos métodos de pressão abdominal, sucção anal, contenção em câmara metabólica ou alimentação forçada, o sacrifício dos animais do método de dissecação intestinal e a lixiviação de nutrientes e de energia, principalmente das fezes. Em um estudo realizado por Abimorad (2001), foram avaliados quatro métodos de coleta de fezes (dissecação, extrusão, sistema de Ghelph e sistema de Ghelph modificado), e o tempo mais eficiente para coleta de fezes nos sistemas de Guelph, analisando o coeficiente de digestibilidade da proteína bruta de uma dieta para o pacu (Piaractus mesopotamicus). $\mathrm{O}$ autor relatou que todos os métodos estudados podem ser adotados com segurança, para a espécie estudada, desde que sejam rigorosamente aplicados, e o intervalo de tempo entre as coletas de fezes em estudos de digestibilidade, por intermédio dos sistemas de Guelph, não deve ultrapassar 30 minutos. Como as informações obtidas com uma espécie não devem ser generalizadas exatamente para outras, devido a fatores específicos como comportamento e consistência das fezes, novos estudos deveriam ser realizados e podem ser tão importantes a ponto de impedir a utilização de determinados métodos.

Wilson et al. (1985) compararam os coeficientes de digestibilidade aparente de nutrientes para alevinos de bagre do canal (Ictalurus punctatus), alimentados com dietas-teste extrusadas e peletizadas elaboradas com milho, farelo de algodão, farinha de peixe, carne e ossos, farelo de arroz, arroz moído, farelo de soja e trigo. Foram observadas poucas diferenças na digestibilidade de energia dos alimentos e, também, os valores determinados com o uso das dietas-teste peletizadas pareciam ser de maior confiança em comparação às extrusadas. No estudo de Khan (1994), com o bagre tropical Myptus nemurus, os coeficientes de digestibilidade aparente, da proteína, da matéria seca e da energia de seis ingredientes (farinha de 
peixe, farelo de soja, farelo de arroz, farinha de côco, milho e vísceras de aves) não diferiram significativamente, exceto para o milho e vísceras de aves que apresentaram os piores valores.

O presente trabalho foi conduzido com o objetivo de determinar os coeficientes de digestibilidade aparente da fração protéica e da energia dos principais alimentos utilizados na alimentação do pintado.

\section{Material e Métodos}

O presente trabalho foi realizado no Laboratório de Nutrição de Organismos Aquáticos do Centro de Aquicultura da UNESP, Campus de Jaboticabal, de fevereiro de 2000 a fevereiro de 2001.

\section{Material biológico}

Foram adquiridos inicialmente 600 alevinos de pintado, com peso médio inicial de $9,80 \pm 1,48 \mathrm{~g}$ e comprimento total médio de $13,00 \pm 1,00 \mathrm{~cm}$. Estes foram adquiridos de empresa especializada e já estavam treinados para receber alimentação artificial. Ainda assim, passaram por um período de adaptação de 30 dias ao ambiente e à dieta referência (Tabela 1). Quando já totalmente adaptados, foram selecionados 390 peixes para início do período experimental. Para alcançar composição de nutrientes próxima das usadas em dietas comerciais, foram utilizados, um alimento protéico de origem animal (farinha de peixe), outro de origem vegetal (farelo de soja), dois energéticos (milho e farelo de trigo) e uma fonte de lipídeos (óleo de soja), além de um suplemento mineral e vitamínico.

Condições ambientais

Os alevinos foram estocados em 39 aquários de alimentação, constituídos de caixas de fibrocimento com volume de 100 litros, dotados de fluxo de água e aeração contínuos, numa densidade de 10 peixes/ aquário. A água utilizada era proveniente de poço artesiano e, com isso, sua temperatura naturalmente foi mantida em torno de $28^{\circ} \mathrm{C}$.

Todos aquários tiveram a temperatura aferida diariamente, de manhã, usando-se termômetros de bulbo de mercúrio graduados de 0 a $50^{\circ} \mathrm{C}$. Semanalmente, foram realizadas análises de $\mathrm{pH}$, com peagômetro, e de concentração de oxigênio dissolvido, usando-se um oxímetro.

\section{Análise bromatológica dos alimentos}

Para o presente estudo foram escolhidos 12 alimentos (cedidos por indústrias de ração) dentre os
Tabela 1 - Fórmula e composição da dieta de referência Table 1 - Formula and composition of the reference diet

\begin{tabular}{|c|c|}
\hline $\begin{array}{l}\text { Ingrediente } \\
\text { Imgredient }\end{array}$ & $\begin{array}{c}\% \text { dieta } \\
\% \text { diet }\end{array}$ \\
\hline $\begin{array}{l}\text { Farinha de peixe } \\
\text { Fish meal }\end{array}$ & 52,00 \\
\hline $\begin{array}{l}\text { Farelo de soja } \\
\text { Soybean meal }\end{array}$ & 21,50 \\
\hline $\begin{array}{l}\text { Farelo de trigo } \\
\text { Wheat meal }\end{array}$ & 8,00 \\
\hline $\begin{array}{l}\text { Milho } \\
\text { Corn }\end{array}$ & 13,50 \\
\hline Óleo de soja & 4,00 \\
\hline $\begin{array}{l}\text { Suplemento vitamínico e mineral }{ }^{1} \\
\text { Vitamin and mineral supplement } \\
\text { Composição calculada }^{2} \\
\text { Calculated composition }\end{array}$ & 1,00 \\
\hline $\begin{array}{l}\text { Proteína bruta }(\%) \\
\text { Crude protein }\end{array}$ & 40,00 \\
\hline $\begin{array}{l}\text { Extrato etéreo }(\%) \\
\text { Ether extract }\end{array}$ & 8,11 \\
\hline $\begin{array}{l}\text { Fibra bruta (\%) } \\
\text { Crude fiber }\end{array}$ & 2,30 \\
\hline $\begin{array}{l}\text { Energia bruta }(\mathrm{kcal} / \mathrm{kg}) \\
\text { Gross energy }(\mathrm{kcal} / \mathrm{kg})\end{array}$ & 4165,00 \\
\hline
\end{tabular}

${ }_{1}$ Composição do suplemento mineral e vitamínico: Ferro $15.000 \mathrm{mg}$, Cobre $5.000 \mathrm{mg}$, lodo $500 \mathrm{mg}$, Manganês $17.000 \mathrm{mg}$, Zinco $12.000 \mathrm{mg}$, Selênio $70 \mathrm{mg}$, veículo $1000 \mathrm{~g}$, Vitamina A $12.000 \mathrm{UI}$, Vitamina $D_{3} 1500 \mathrm{UI}$, Vitamina $E 50 \mathrm{mg}$, Vitamina K $4 \mathrm{mg}$, Vitamina $B_{12} 7 \mathrm{mg}$, Vitamina $B_{2} 7 \mathrm{mg}$, Ácido pantotênico $60 \mathrm{mg}$, Ácido nicotínico $120 \mathrm{mg}$, Cloreto de colina $600 \mathrm{mg}$, Metionina $700 \mathrm{mg}$, Antioxidante $500 \mathrm{mg}$, Veículo $1000 \mathrm{~g}$.

${ }^{2}$ Composição calculada com base nos dados obtidos em análises realizadas no Laboratório de Nutrição de Organismos Aquáticos do CAUNESP, Jaboticabal, segundo AOAC (1975).

${ }^{1}$ Mineral and vitamin supplement composition: Iron 15,000 mg, Copper 5,000 mg, lodine $500 \mathrm{mg}$, Manganese 17,000 mg, Zinc 12,000 mg, Seleniun $70 \mathrm{mg}$, vehicle $1000 \mathrm{~g}$, Vitamin A 12,000 UI, Vitamin $D_{3} 1,500 \mathrm{UI}$, Vitamin E $50 \mathrm{mg}$, Vitamin $K 4 \mathrm{mg}$, Vitamin $B_{12} 7 \mathrm{mg}$, Vitamin $B_{2} 7 \mathrm{mg}$, Panthotenic acid $60 \mathrm{mg}$, Nicotinic acid $120 \mathrm{mg}$, Choline chloride $600 \mathrm{mg}$, Methionine $700 \mathrm{mg}$. Antioxidant $500 \mathrm{mg}$, Vehicle $1000 \mathrm{~g}$

${ }^{2}$ Calculated composition based on the analyses performed at the Aquatic Organisms Nutrition Lab of CAUNESP, Jaboticabal, according to AOAC (1975).

mais usados em dietas comerciais para peixes: quatro concentrados protéicos de origem animal (farinhas de peixe, de vísceras de aves, de sangue e penas de aves), três de origem vegetal (farelo de soja e, as sojas integrais crua e tostada) e cinco energéticos (milho, farelos de trigo e de arroz, sorgo com baixo teor de tanino e quirera de arroz).

Todos os ingredientes protéicos e energéticos utilizados nas dietas-teste foram analisados quanto à sua composição bromatológica, conforme metodologia descrita pela AOAC (1965). As análises de energia bruta foram determinadas por intermédio da queima das amostras em bomba calorimétrica. Todas análi- 
ses foram realizadas no Laboratório de Nutrição de Organismos Aquáticos da UNESP, Campus de Jaboticabal-SP e no Laboratório de Análises de Alimentos do Departamento de Zootecnia da FCAV.

As dietas-teste utilizadas para a determinação dos coeficientes de digestibilidade foram compostas pela dieta de referência (em $69,5 \%$ ), por $0,5 \%$ de óxido crômico, utilizado como marcador inerte, e em $30,0 \%$, por um dos ingredientes estudados. Para o seu processamento, às dietas foram acrescidos, exatamente, 50,0\% de água, facilitando a peletização, realizada em moedor de carne. As dietas umedecidas foram então transferidas para sacos plásticos que eram preenchidos de ar e sofriam pequena agitação, para a formação de grânulos simétricos $(0,49 \mathrm{~mm}$ de diâmetro). Após, as dietas foram transferidas para congeladores, para sua conservação.

\section{Coleta das fezes e análises}

Para coleta das fezes dos peixes, realizadas três dias após o seu arraçoamento com as dietasteste, foram utilizados seis coletores construídos segundo o sistema de Guelph modificado, como descrito por Gonçalves (1998), utilizando incubadoras de fibra de vidro de 80 litros de capacidade. Nas extremidades inferiores cônicas foram acoplados registros de esfera, adaptados com pequenas mangueiras de látex, que permitiam a fixação de tubos de ensaio, para a deposição das fezes dos peixes.

Após três dias de alimentação com as dietas-teste, todos os peixes das unidades experimentais, em grupos constituídos de dois tratamentos e suas três repetições, de cada vez, foram levados para os seis aquários de coleta de fezes, exceto para o último grupo (três parcelas). Sempre no período da manhã, as fezes de cada parcela foram coletadas em intervalos de 30 minutos (para evitar perdas por lixiviação), até que fossem recolhidas quantidades suficientes de cada amostra. Esses materiais foram recolhidos em tubos plásticos, etiquetados e levados ao congelador. Após o término da coleta de todas as amostras, as fezes foram secas em estufa com circulação de ar à $65,0^{\circ} \mathrm{C}$, até a obtenção de peso constante, para posterior análise dos teores de proteína e de energia bruta.

Determinação dos coeficientes de digestibilidade aparente

Os coeficientes de digestibilidade aparente (CDa) da proteína e da energia bruta, tanto para a dieta referência quanto para as dietas-teste, foram calculados pela seguinte fórmula:
$D a(\%)=100-100 *\left(\frac{\% \text { indicador na dieta }}{\% \text { indicador nas fezes }} * \frac{\% \text { nutriente } \text { nas fezes }}{\% \text { nutriente na dieta }}\right)$

O teor de óxido crômico usado como indicador foi determinado pelo método de digestão com ácido nítrico e perclórico, com leitura em espectofotômetro, segundo Furukawa \& Tsukahara (1976). Os teores de proteína bruta foram obtidos pelo método de micro-Kjeldahl, por meio da multiplicação das porcentagens de nitrogênio total pelo fator 6,25. A quantidade de energia bruta foi determinada pela queima das amostras em bomba calorimétrica.

Os valores de digestibilidade aparente para a energia e proteína dos ingredientes estudados foram determinados por intermédio de metodologia descrita por Cho et al. (1982), baseada na proporção de 70:30 de mistura da dieta referência e ingrediente teste, segundo a fórmula:

$$
\mathrm{CDa}(\%)=100 / 30 \times[\text { teste }-70 / 100 \times \text { referência }]
$$

em que: CDa é o coeficiente de digestibilidade aparente do nutriente do alimento estudado; teste, o resultado de digestibilidade do nutriente na sua dietateste; e referência, o valor de digestibilidade do nutriente na dieta de referência.

Delineamento experimental

Para comparação entre os coeficientes de digestibilidade para os alimentos estudados, nas análises de variância (ANOVA) e nas aplicações do teste de Tukey, a $5 \%$ de probabilidade, foi utilizado o delineamento inteiramente casualizado com 12 tratamentos, correspondentes a quatro ingredientes protéicos de origem animal, três de origem vegetal e cinco energéticos, com três repetições.

Os resultados foram analisados, utilizando-se o programa ESTAT, desenvolvido pelo polo computacional da FCAV de Jaboticabal - UNESP.

\section{Resultados e Discussão}

\section{Condições ambientais}

Os valores médios observados para os parâmetros de água, mantiveram-se dentro dos padrões recomendáveis para o cultivo de peixes de clima tropical: (médias de oxigênio dissolvido de 5,50 $\pm 1,35 \mathrm{mg} / \mathrm{L} \mathrm{e}$ temperatura de $29,0 \pm 1,5^{\circ} \mathrm{C}$.) A temperatura média observada para todo o período experimental encontra-se dentro dos limites recomendados por Marques et al. (1992), para o pintado $\left(30,1^{\circ} \mathrm{C}\right)$. 


\section{Composição dos alimentos}

Observa-se, na Tabela 2, que os valores analisados estão próximos aos encontrados em tabelas disponíveis na literatura (EMBRAPA, 1991; NRC, 1993).

Coeficientes de digestibilidade aparente (CDA) da proetína e energia dos alimentos estudados.

Os resultados observados para os coeficientes de digestibilidade aparente dos alimentos estudados são apresentados na Tabela 3 .

Observa-se que os alevinos apresentaram médias para os coeficientes de digestibilidade da fração protéica, em geral, muito baixas para os alimentos. Somente a farinha de peixe mostrou bom aproveitamento deste nutriente. Esta absorção pode ser considerada ótima, quando comparada com a apresentada pelo "red drum" (Sciaenops ocellatus) em estudo feito por Gaylord \& Gatlin III (1996), em que a média de digestibilidade aparente da proteína da farinha de peixe foi de $87,9 \%$. Comparando-se com a do bagre do canal, o coeficiente de digestibilidade da proteína foi tão bom quanto o observado por Joshua \& Rebecca (2000), de 89,3\%, e por Brown \& Strang (1985), de 86,0\%, que usaram farinhas de peixe de melhor qualidade.

Os produtos de soja apresentaram valores médios para os coeficientes de digestibilidade da proteína bem diferentes entre si $(\mathrm{P}<0,05)$, mostrando a eficiência crescente com a destruição de fatores antinutricionais pelos processamentos de tostagem (assim como no estudo realizado com o pacu, por Stech (1999), e a extração de óleo. Outros processamentos, combinados ou não com a composição desfavorável de alguns nutrientes, como o excesso de ferro na farinha de sangue obtida por tostagem, o balanço inadequado de aminoácidos da farinha de penas, a presença de inibidores da protease ácido fítico, saponinas, taninos e polissacarídeos não amiláceos em produtos de origem vegetal (Francis et al., 2001) poderiam justificar valores de proteína digestível muito baixos, inviabilizando a utilização destes produtos como fonte protéica na alimentação do pintado. Seus coeficientes de digestibilidade da proteína foram piores, até mesmo que alguns energéticos como o milho, que teve aproveitamento satisfatório $(64,2 \%)$. Com-

Tabela 2 - Composição bromatológica analisada dos alimentos

Table 2- Feedstuffs bromatological composition

\begin{tabular}{|c|c|c|c|c|c|c|c|c|}
\hline $\begin{array}{l}\text { Ingrediente }^{1} \\
\text { Ingredient }\end{array}$ & $\begin{array}{l}\text { IFN }^{1} \\
I F N^{1}\end{array}$ & $\begin{array}{l}\text { MS (\%) } \\
D M(\%)\end{array}$ & $\begin{array}{l}\mathrm{PB}(\%) \\
C P(\%)\end{array}$ & $\begin{array}{l}\mathrm{FB}(\%) \\
C F(\%)\end{array}$ & $\begin{array}{l}\mathrm{EE}(\%) \\
E E(\%)\end{array}$ & $\begin{array}{c}\mathrm{MM}(\%) \\
\text { Ash (\%) }\end{array}$ & $\begin{array}{l}\mathrm{ENN}(\%) \\
F N E(\%)\end{array}$ & $\begin{array}{l}\mathrm{EB}(\mathrm{kcal} / \mathrm{kg}) \\
G E(k c a l / k g)\end{array}$ \\
\hline $\begin{array}{l}\text { Farinha de peixe } \\
\text { Fish meal }\end{array}$ & $5-09-835$ & 94,88 & 53,93 & 0,00 & 5,53 & 28,87 & 6,55 & 3833,00 \\
\hline $\begin{array}{l}\text { Farelo de soja } \\
\text { Soybean meal }\end{array}$ & $5-04-604$ & 89,36 & 45,99 & 5,57 & 0,89 & 5,17 & 31,74 & 4392,55 \\
\hline $\begin{array}{l}\text { Milho } \\
\text { Corn }\end{array}$ & $4-02-935$ & 88,38 & 9,13 & 2,17 & 4,30 & 1,35 & 71,53 & 4144,01 \\
\hline $\begin{array}{l}\text { Farinha vísceras aves } \\
\text { Poultry by-product }\end{array}$ & $5-03-798$ & 95,37 & 58,60 & 0,00 & 4,00 & 18,69 & 14,08 & 4489,03 \\
\hline $\begin{array}{l}\text { Soja tostada } \\
\text { Soybean (whole, tosted) }\end{array}$ & - & 94,45 & 37,06 & 3,34 & 22,92 & 4,70 & 26,43 & 5438,34 \\
\hline $\begin{array}{l}\text { Farelo de trigo } \\
\text { Wheat meal }\end{array}$ & $4-05-190$ & 87,55 & 16,34 & 8,12 & 4,88 & 4,78 & 53,43 & 4257,76 \\
\hline $\begin{array}{l}\text { Sorgo } \\
\text { Sorghum }\end{array}$ & 4-04-444 & 88,35 & 9,14 & 0,52 & 2,30 & 1,67 & 74,72 & 3719,10 \\
\hline $\begin{array}{l}\text { Farelo de arroz } \\
\text { rice meal }\end{array}$ & $4-03-928$ & 90,87 & 13,40 & 7,22 & 17,44 & 8,50 & 44,31 & 4489,03 \\
\hline $\begin{array}{l}\text { Quirera de arroz } \\
\text { Ground rice }\end{array}$ & - & 88,73 & 9,73 & 0,00 & 1,21 & 0,46 & 77,33 & 3841,00 \\
\hline $\begin{array}{l}\text { Farinha de penas } \\
\text { Feather meal }\end{array}$ & $5-03-795$ & 91,58 & 79,20 & 0,00 & 7,44 & 2,88 & 2,06 & 5227,41 \\
\hline $\begin{array}{l}\text { Soja crua } \\
\text { Soybean (whole, raw) }\end{array}$ & 5-04-597 & 90,69 & 39,58 & 4,80 & 13,89 & 4,27 & 28,15 & 5086,27 \\
\hline $\begin{array}{l}\text { Farinha de sangue } \\
\text { Blood meal }\end{array}$ & $5-00-381$ & 92,19 & 73,44 & 0,00 & 3,69 & 9,35 & 5,71 & 4831,75 \\
\hline
\end{tabular}

\footnotetext{
1 International Feed Number ( NAS/NRC)

$2 \mathrm{MS}=$ matéria seca, $\mathrm{PB}=$ proteína bruta, $\mathrm{FB}=$ fibra bruta, $\mathrm{EE}=$ extrato etéreo, $\mathrm{MM}=$ matéria mineral, $\mathrm{ENN}=$ extrativo não nitrogenado, $\mathrm{EB}=$ energia bruta.

${ }^{2} D M=$ dry matter, $C P=$ crude protein, $C F=$ crude fiber, $E E=$ ether extract, $A$ sh $=$ ashes, $F N E=$ free nitrogen extract, $G E=$ gross energy.
} 
parando-se com a digestibilidade apresentada para este nutriente, por uma espécie tropical de hábito alimentar onívoro, o matrinchã, que mostrou um coeficiente médio de 70,8\% (Sallum, 2000) em diferentes períodos do ano.

Considerando-se o hábito alimentar carnívoro da espécie estudada, foram observados valores satisfatórios para os coeficientes de digestibilidade da energia (Tabela 3), destacando-se as médias observadas para a farinha de peixe, as sojas processadas e até mesmo os principais concentrados energéticos estudados (milho e os farelos de trigo e de arroz). A farinha de peixe também foi o ingrediente com melhor digestibilidade de energia. Estes coeficientes foram semelhantes aos encontrados em estudo de digestibilidade de energia para o "australian silver perch" (Bidyanus bidyanus), que apresentou melhor coeficiente de digestibilidade para a farinha de peixe australiana $(89,6 \%)$ e menores médias para a energia do milho (55,2\%), do sorgo $(37,8 \%)$ e do trigo (53,2\%), segundo Allan et al. (2000).

Comparando com os dados observados para os alevinos de pintado, Khan (1994) encontrou, para outro bagre tropical, o Mystus nemurus, elevados coeficientes de digestibilidade para proteína bruta da farinha de peixe $(97,8 \%)$, farelo de soja $(86,0 \%)$ e arroz $(81,0 \%)$ e resultados muito inferiores para o milho $(51,9 \%)$ e vísceras de aves $(37,0 \%)$. Em relação aos coeficientes de digestibilidade da energia bruta, os autores encontraram resultados próximos aos observados nesse estudo com o pintado, a não ser para o farelo de arroz $(67,9 \%)$, a farinha de peixe $(77,8 \%)$, o farelo de soja $(67,89 \%)$ e o milho $(63,40 \%)$. No entanto, a elevada digestibilidade protéica da farinha de peixe $(97,8 \%)$ denota possível ocorrência de lixiviação desse nutriente, que pode ter superestimado seu resultado de digestibilidade.

No estudo de Wilson \& Poe (1985), juvenis de bagre do canal apresentaram coeficiente de digestibilidade aparente da proteína para a farinha de

Tabela 3 - Valores médios para a digestibilidade da proteína e da energia dos principais ingredientes utilizados em dietas práticas para o pintado

Table 3 - Average values of energy and protein digestibilty of the ingredients used in practical diets for pintado

\begin{tabular}{|c|c|c|c|c|c|c|}
\hline \multirow[t]{2}{*}{$\begin{array}{l}\text { Ingredientes } \\
\text { Ingredients }\end{array}$} & \multicolumn{3}{|c|}{$\begin{array}{l}\text { Proteína } \\
\text { Protein }\end{array}$} & \multicolumn{3}{|c|}{$\begin{array}{l}\text { Energia } \\
\text { Energy }\end{array}$} \\
\hline & $\begin{array}{l}\% \mathrm{~PB} \\
\% C P\end{array}$ & $\begin{array}{l}\mathrm{Da}(\%)^{1} \\
\operatorname{Ad}(\%)\end{array}$ & $\begin{array}{l}\mathrm{PD}(\%) \\
D P(\%)\end{array}$ & $\begin{array}{l}\mathrm{EB}(\mathrm{kcal} / \mathrm{kg}) \\
G E(\mathrm{kcal} / \mathrm{kg})\end{array}$ & $\begin{array}{c}\mathrm{Da}(\%)^{* *} \\
\operatorname{Ad}(\%)\end{array}$ & $\begin{array}{l}\mathrm{ED}(\mathrm{kcal} / \mathrm{kg} \\
D E(\mathrm{kcal} / \mathrm{kg}\end{array}$ \\
\hline $\begin{array}{l}\text { Farinha de peixe } \\
\text { Fish meal }\end{array}$ & 53,93 & $84,14^{\mathrm{a}}$ & 45,38 & 3833,00 & $72,80^{\mathrm{a}}$ & 2790,42 \\
\hline $\begin{array}{l}\text { Farelo de soja } \\
\text { Soybean meal }\end{array}$ & 45,99 & $67,10^{\mathrm{b}}$ & 30,86 & 4392,55 & $61,66^{b c}$ & 2708,45 \\
\hline $\begin{array}{l}\text { Milho } \\
\text { Corn }\end{array}$ & 9,13 & $64,18^{b c}$ & 5,86 & 4144,01 & $64,95^{\mathrm{b}}$ & 2691,53 \\
\hline $\begin{array}{l}\text { Farinha vísceras de aves } \\
\text { Poultry by-product }\end{array}$ & 58,60 & $61,59^{\mathrm{c}}$ & 36,09 & 4489,03 & $48,98^{\mathrm{ef}}$ & 2198,73 \\
\hline $\begin{array}{l}\text { Soja tostada } \\
\text { Soybean (whole, tosted) }\end{array}$ & 37,06 & $49,48^{\mathrm{d}}$ & 18,34 & 5438,34 & $57,39^{\mathrm{cd}}$ & 3121,06 \\
\hline $\begin{array}{l}\text { Farelo de trigo } \\
\text { Wheat meal }\end{array}$ & 16,34 & $49,47^{\mathrm{d}}$ & 8,08 & 4257,76 & $53,20 \mathrm{de}$ & 2265,13 \\
\hline $\begin{array}{l}\text { Sorgo } \\
\text { Sorghum }\end{array}$ & 9,14 & $44,87^{\mathrm{e}}$ & 4,10 & 3719,10 & $48,35^{\mathrm{ef}}$ & 1798,18 \\
\hline $\begin{array}{l}\text { Farelo de arroz } \\
\text { Rice meal }\end{array}$ & 13,40 & $44,21^{\mathrm{e}}$ & 5,92 & 4489,03 & $51,84^{\mathrm{def}}$ & 2327,11 \\
\hline $\begin{array}{l}\text { Quirera de arroz } \\
\text { Ground rice }\end{array}$ & 9,73 & $43,24 \mathrm{ef}^{\mathrm{f}}$ & 4,21 & 3841,00 & $47,34^{\mathrm{ef}}$ & 1818,33 \\
\hline $\begin{array}{l}\text { Farinha de penas } \\
\text { Feather meal }\end{array}$ & 79,20 & $39,56^{\mathrm{f}}$ & 31,33 & 5227,41 & $51,26^{\mathrm{def}}$ & 2679,57 \\
\hline $\begin{array}{l}\text { Soja crua } \\
\text { Soybean (whole, raw) }\end{array}$ & 39,58 & $26,84^{\mathrm{g}}$ & 10,62 & 5086,27 & $45,55^{\mathrm{f}}$ & 2316,80 \\
\hline $\begin{array}{l}\text { Farinha de sangue } \\
\text { Blood meal }\end{array}$ & 73,44 & $10,47^{\mathrm{h}}$ & 7,69 & 4831,75 & $16,08^{\mathrm{g}}$ & 776,95 \\
\hline
\end{tabular}

${ }_{1}^{1}$ Médias seguidas pela mesma letra não diferem $(P>0,05)$ pelo teste Tukey.

${ }^{1}$ Means followed by the same letter did not differ $(P>.05)$ by Tukey test.

R. Bras. Zootec., v.32, n.4, p.779-786, 2003 
peixe $(85,0 \%)$, semelhante ao determinado para o pintado nesse estudo, e ainda melhor aproveitamento para a energia dessa farinha $(92,0 \%)$. Para os demais alimentos estudados (milho, farelo de algodão, farinha de carne e ossos, quirera de arroz, farelo de soja e trigo), esses autores encontraram altos coeficientes de digestibilidade aparente da proteína bruta de 97,0; 83,$0 ; 85,0 ; 73,0 ; 97,0$ e $92,0 \%$, respectivamente, que denotam a lixiviação de nutrientes na água (exceto para o farelo de arroz 63,0\%). No estudo de Wilson \& Poe (1985), coeficientes de digestibilidade aparente da energia do milho $(57,0 \%)$ e farelo de arroz $(14,0 \%)$ apresentaram-se piores que os encontrados para o pintado, apesar de terem sido observados melhores valores para o farelo de soja $(72,0 \%)$ e farelo de trigo $(63,0 \%)$.

Para uma espécie marinha de hábito alimentar carnívoro, o "red drum" (Sciaenops ocellatus), McGoogan \& Reigh (1996) determinaram coeficientes de digestibilidade aparente para a proteína bruta superiores aos encontrados para o pintado: farinha de peixe $(95,9 \%)$, milho em grão $(81,5 \%)$, sorgo $(77,8 \%)$, farelo de soja $(80,2 \%)$, farelo de trigo $(87,3 \%)$ e arroz $(77,1 \%)$. De forma contrária, os coeficientes de digestibilidade aparente para a energia foram piores: farinha de peixe $(60,1 \%)$, milho em grão $(55,9 \%)$, farelo de soja (37,7\%), farelo de trigo $(33,6 \%)$ e arroz $(11,9 \%)$, exceto para o sorgo $(52,6 \%)$.

Comparados com os resultados observados com os alevinos de pintado (Tabela 03), os coeficientes de digestibilidade da proteína e da energia dos ingredientes de rações determinados por Sullivan \& Reigh (1995), para a espécie marinha, carnívora, o híbrido de "striped bass" (Morone saxatilis x Morone chrysops), foram maiores, respectivamente, para as farinha de peixe $(95,5$ e $88,2 \%)$, farelos de soja $(79,9$ e $55,2 \%)$, de trigo $(91,9$ e $60,7 \%$ ) e milho $(86,7$ e $40,6 \%)$. Os valores de digestibilidade aparente para proteína bruta e energia dos alimentos determinados para o pintado podem ser considerados relativamente baixos, a não ser para a digestibilidade da proteína da farinha de peixe e da energia do farelo de soja e do milho.

\section{Conclusões}

Com base nos coeficientes de digestibilidade aparente da proteína determinados para os alevinos de pintado, os alimentos que se apresentaram melhores foram: farinha de peixe $(84,14 \%)$, farelo de soja $(67,10 \%)$, milho $(64,18 \%)$ e farinhas de vísceras de aves $(61,25 \%)$. Os piores resultados foram observa- dos para os coeficientes das farinhas de sangue e de penas (10,47 e 39,56\%, respectivamente).

Para farinha de pexe, milho, soja integral tostada e os farelos de soja, trigo e arroz, foram observadas as melhores médias de coeficientes de digestibilidade da energia: 72,80;57,39; 64,95; 61,66; 53,20 e 51,84 , respectivamente.

A farinha de peixe apresentou-se como o melhor ingrediente para o pintado $(45,38 \%$ PD e $2790,42 \mathrm{kcal}$ $\mathrm{ED} / \mathrm{kg})$, seguido do farelo de soja $(30,86 \% \mathrm{PD}$ e $2708,45 \mathrm{kcal} \mathrm{ED} / \mathrm{kg})$, da soja integral tostada $(18,34 \%$ $\mathrm{PD}$ e $3121,06 \mathrm{kcal} \mathrm{ED} / \mathrm{kg}$ ), do milho $(5,86 \% \mathrm{PD}$ e $2691,53 \mathrm{kcal} \mathrm{ED} / \mathrm{kg})$ e do farelo de trigo $(8,08 \% \mathrm{PD}$ e $2265,13 \mathrm{kcal} \mathrm{ED} / \mathrm{kg}$ ).

\section{Literatura Citada}

ABIMORAD, E.G. Métodos de coleta de fezes e determinação dos coeficientes de digestibilidade da fração protéica e da energia bruta dos principais alimentos utilizados em dietas comerciais para o crescimento do pacu, Piaractus mesopotamicus (Holmberg, 1887). Jaboticabal,: Universidade Estadual Paulista, 2001. 52p. Monografia (Graduação em Zootecnia) - Universidade Estadual Paulista, 2001.

ALBERNAZ, N.D.S. Efeito do processamento da ração sobre os valores de digestibilidade aparente dos nutrientes para Piau Verdadeiro (Leporinus elongatus Cuv \& Val, 1864). Lavras: Universidade Federal de Lavras, 2000. 54p. Dissertação (Mestrado em Zootecnia) - Universidade Federal de Lavras, 2000.

ALLAN, G.L.; PARKINSON, S.; BOOTH, M.A. et al. Replacement of fish meal in diets for australian silver perch, Bidyanus: I. Digestibility of alternative ingredients. Aquaculture, v.186, p.293-310, 2000.

ASSOCIATION OF OFFICIAL AGRICULTURAL CHEMISTS - AOAC. Official methods of analysis of the association of official agricultural chemists. Washington, D.C.: 1965.937p.

BROWN, P.B.; STRANG, R.J. Protein digestibility coefficients for yearling channel catfish fed high protein feedstuffs. The Progressive Fish Culturist, v.47, n.2, p.94-97, 1985.

CHO, C.Y.; SLINGER, S.J.; BAYLEY, H.S. Bioenergetics of salmonid fishes: energy intake, expenditure and productivity. Comparative Biochemistry Physiology, v.73, p.25-41, 1982.

EMPRESA BRASILEIRA DE PESQUISA AGROPECUÁRIAEMBRAPA. Tabela de composição química e valores energéticos de alimentos para suínos e aves. 3.ed. Concórdia: 1991. 97p.

FRANCIS, G.; MAKKAR, H.P.S.; BECKER, K. Antinutritional factors present in plant-derived alternate fisch feed ingredients and their effects ins fish. Aquaculture, v.199, p.197-227, 2001.

FURUKAWA, A.; TSUKAHARA, H. On the acid digestion method for the determination of Chromic Oxyde as an index substance in the study of digestibility of fish feed. Bulletin of the Japanese Society Scientific Fisheries, v.32, n.6, p.502-506, 1976

GAYLORD, G.T.; GATLIN III, D.M. Determination of digestibility coefficients of various feedstuffs for red drum (Sciaenops ocellatus).Aquaculture, v.139, p.303-314, 1996. GONÇALVES, E.G. Determinação do tempo de trânsito

R. Bras. Zootec., v.32, n.4, p.779-786, 2003 
gastrointestinal e coeficientes de digestibilidade aparente da proteína bruta de uma ração para juvenis de pintado, Pseudoplatystoma coruscans (Agassiz,1829). Marília: Universidade de Marília, 1998. 23p. Monografia (Graduação em Zootecnia) - Universidade de Marília, 1998.

JOSHUA, R.; REBECCA, L. Comparative aspects of feed and feedstuff by yaqui and channel catfish. North American Journal of Aquaculture, v.62, n.4, p.279-284, 2000.

KHAN, M.S. Apparent digestibility coefficients for common in formulated diets for tropical catfish, Mystus nemurus (Cuvier $\&$ Valenciennes). Aquaculture and Fisheries Management, v.25, p.167-174, 1994.

MARQUES, E.E.; AGOSTINHO, A.A.; SAMPAIO, A.A. et al. Alimentação, evacuação gástrica e cronologia da digestão de jovens de pintado Pseudoplatystoma coruscans (Siluriforme, Pimelodide) e suas relações com a temperatura ambiente. Revista Unimar, v.14, p.207-221, 1992.

McGOOGAN, B.B.; REIGH, R.C. Apparent digestibility of selected ingredients in red drum (Sciaenops ocellatus) diets. Aquaculture, v.141, p.233-244, 1996.

NATIONAL RESEARCH COUNCIL - NRC. Nutrients requirements of fish. Washington, D.C.: National Academy Press, 1993. $114 \mathrm{p}$.

RESENDE, E.K.; CATELA, C.A.; NASCIMENTO, L.F. et al. Biologia do Curimbatá (Prochilodus lineatus), Pintado (Pseudoplatystoma coruscans) e Cachara (Pseudoplatystoma fasciatum) na Bacia Hidrográfica do rio Miranda, Pantanal do Mato Grosso do Sul, Brasil. In: CONGRESSO BRASILEIRO DE ZOOLOGIA, 1990, Cuiabá. Resumos... Cuiabá: 1990. p. 140

SEIXAS FILHO, J.T.; BRÁS, J.M.; GOMIDE, A.T.M. et al. Anatomia funcional e morfologia do intestino no Teleostei (Pisces) de água doce Surubim (Pseudoplatystoma coruscansAgassiz, 1829). Revista Brasileira de Zootecnia, v.30, n.6, p.1670-1680, 2001.
RODRIGUES, A.M.P. Digestibility studies in fish: a review. Instituto de Zoologia Dr. Augusto Nobre, Série Monografias, n.6, p.29, 1994.

SALLUM, W.B. Óxido crômico III como indicador externo em ensaios metabólicos para o matrinchã (Bricon cephalus, Gunther 1869) (Teleostei, Characidae). Lavras: UniversidadeFederal de Lavras, 2000. 116p. Tese(Doutorado em Zootecnia) - Universidade Federal de Lavras, 2000.

SOUZA, R.R.P. Digestibilidade aparente da proteína de dietas para o híbrido de pacu (Piaractus mesopotamicus) e Tambaqui (Colossoma macropomum). Piracicaba: Escola Superior de Agricultura Luiz de Queiroz, 1989. Dissertação (Mestrado em Agronomia) - Escola Superior de Agricultura Luiz de Queiroz, 1989.

SULLIVAN, J.A.; REIGH, R.C. Apparent digestibility of selected feedstuffs in diets for hybrid striped bass (Morone saxatilis femeaX Morone chrysops). Aquaculture, v.138, p.313-332, 1995.

STECH, M.R. Utilização da soja integral processada em dietas para o crescimento de pacu, Piaractus mesopotamicus (Holmberg, 1887). Jaboticabal: Universidade Estadual Paulista, 1999. 90p. Dissertação (Mestrado em Zootecnia) Universidade Estadual Paulista, 1999.

WILSON, R.P.; POE, W.E. Apparent digestibility protein and energy coefficients of common feed ingredients for Channel Catfish. The Progressive Fish Culturist, v.47, n.3, p.155-158, 1985.

Recebido em: 23/07/02 Aceito em: 05/12/02 